INTERNATIONAL JOURNAL OF SYSTEMATIC BACTERIOLOGY

Vol. 17, No. 4

October 1967

pp. $343-360$

\title{
A REVISED DESCRIPTION OF MORAXELLA POLYMORPHA FLAMM 1957, WITH A PROPOSAL OF A NEW NAME, MORAXELLA PHENYLPYROUVICA FOR THIS SPECIES
}

\author{
Kjell Bovre and S. D. Henriksen
}

Kaptein W. Wilhelmsen og F rues Bakteriologiske Institutt, University of Oslo, Rikshospitalet, Oslo

ABSTRACT. Detailed studies of a group of strains, the $752 / 52 \mathrm{group}$, which was previously believed to belong to Moraxella nonliquefaciens show that these strains constitute a distinct entity deserving the status of a species. It is distinguishable from M. nonliquefaciens and $M$. osloensis as well as from a number of otherstrains of Moraxella or Moraxella-like organisms by strong urease activity and by deamination of phenylalanine and of tryptophan. It is practically incompatible with the two former species in streptomycinresistance transformation. Among a large number of other strains tested for ability to deaminate phenylalanine and tryptophan, the strain $1078 / 55$, described by Flamm in 1957 under the name Moraxella polymorpha, was exceptional in giving positive results. This strain was found to agree with the $752 / 52$ group in all characters studied except urease production, and it is believed that this strain must be considered to belong to the same species. It is suggested that the epithet polymorpha in the combination Moraxella polymorpha will cause confusion, is illegitimate, and that the epithet should be rejected. It is proposed to rename the species Moraxella phenylpyrouvica. Since the first strain to be described, strain $1078 / 55$, differs from the others infailing to split urea, it is suggested that a urease positive strain, 2863 , should be designated the neotype strain of this species. The following two questions are referred to the Judicial Commission for Opinions. 
1. Should the epithet polymorpha in the combination Moraxella polymorpha be placedin the list of nomina rejicienda according to Principle 1 (2) and Rule $24 \mathrm{~d}$ of the International Code of Nomenclature of Bacteria?

2. Should the name Moraxella phenylpyrouvica be conserved against Moraxella polymorpha?

A group of strains, which has previously been referred to as the $752 / 52$ group (B $6 v$ re $1967 \mathrm{c}$, B 6 vre and Henriksen $1967 \mathrm{a}, \mathrm{b})$ was studied and found to differ from other Moraxella species, particularly in splitting urea and in deaminating phenylalanine and tryptophan. It was decided that this group of strains deserved the rank of a species.

When a large number of strains of all known species of Moraxella as well as unidentified Moraxella-like strains and species suspected of relationship to Moraxella, were tested for deamination of these amino acids, the strain 1078/55, isolated by Flamm (1957) and described under the name M. polymorpha was found to possess all the characters of the $752 / 52$ group tested for, except urease production, and it was concluded that this strain must also be considered as belonging to the same species as the $752 / 52$ group. For reasons which will be given in the discussion we feel that the use of the epithet polymorpha in this combination is going to cause confusion, and a new name, Moraxella phenylpyrouvica is proposed. The strains are referred to under this name in the following.

\section{Material and Methods}

One of the strains $(752 / 52)$ had been isolated in Oslo by one of us (S. D. H.) in 1952. Seven other strains were received from the late Miss Elizabeth $O$. King. They were known to produce urease, but had not been examined for deamination of amino acids.

The designation and source of the individual strains are as follows: $752 / 52$ (unknown clinical material), 2863 (blood), 5542 (blood), 9158 (blood), 9413 (pus), A 390 (suprapubic ulcer), A1019 (scalp lesion) and A1232(1) (vulva). The strain $1078 / 55$ of Moraxella polymorpha, isolated by Flamm from spinal fluid was added to the material at a relatively late stage when it was found to agree with our strains in all respects except urease production. 
Morphological, cultural and biochemical tests

$20 \mathrm{~h}$ old human blood agar cultures, incubated at $33^{\circ} \mathrm{C}$ and $37^{\circ} \mathrm{C}$ in a humid atmosphere, were used for microscopical examinations, characterization of colonies and detection of haemolysis. The $33^{\circ} \mathrm{C}$ cultures served as material for inoculation of special media and for preparation of suspensions for enzymological tests. If not otherwise stated below, these cultural and biochemical tests were read after 4 days of incubation, which took place at $33^{\circ} \mathrm{C}$ and $37^{\circ} \mathrm{C}$.

The presence of capsules was studied in India ink preparations from $18 \mathrm{~h}$ old cultures at $33^{\circ} \mathrm{C}$ in a semisolid meat infusion broth with $0.2 \%$ agar and $10 \%$ horse serum. Examination for motility was performed microscopically from the same cultures, as well as macroscopically by means of stab cultures in various semisolid media.

Anaerobic growth experiments took place with human blood agar cultures in pure hydrogen atmos phere maintained for 2 days at $33^{\circ} \mathrm{C}$. Heat resistance was studied in a "Heto" water bath, at $4^{\circ}$ intervals from $45^{\circ} \mathrm{C}$ to $65^{\circ} \mathrm{C}$. The strain $1078 / 55$ was not examined. For description of the procedure, Bфvre and Henriksen (1967a) should be consulted.

Tests for growth on Hugh and Leifson's (1953) medium were performed by stab culture and also by means of surface cultures on the same medium after the addition of $1 \%$ agar. The results were read within 1-2 days.

Growth in citrate as sole source of carbon was examined in Koser's medium (Koser 1924, medium no. [2]). The strains were also tested for growth in the defined medium of Audureau (1940), with $1 \%$ ethanol as carbon source.

Longevity was tested at room temperature $\left(20-22^{\circ} \mathrm{C}\right)$ on blood agar plates from which heavy subcultures were made with one week intervals. No precautions were taken as regards desiccation of the plates.

The catalase and oxidase reactions were performed with $3 \%$ hydrogen peroxide, a $1 \%$ aqueous solution of dimethyl-pphenylenediamine hydrochloride and $0.5 \%$ tetramethyl-pphenylenediamine hydrochloride, respectively. The reagents were poured over nutrient agar cultures grown at $33^{\circ} \mathrm{C}$ for $22 \mathrm{~h}$.

The medium for nitrate reduction consisted of $0.02 \%$ nitrite-free $\mathrm{KNO}_{3}$ and $0.5 \%$ Bacto-Peptone in distilled water. In parallel the same medium with $10 \%$ horse serum added, was used. Readings we re made daily for 4 days, and a distinct colour on at least one occasion with the conventional sulfanilic acid-alpha-naphtylamine reagent was considered as a positive result. As in all other tests with fluid media, 
incubation was undertaken without agitation or aeration.

Acid production from glucose was tested for in Hugh and Leifson stab cultures, incubated at $33^{\circ} \mathrm{C}$ for 4 weeks, and on ascites agar slants with $1 \%$ carbohydrate, $24 \%$ ascites and phenol red indicator. Tests were also performed with maltose replacing glucose in the latte $r$ medium. The ascites agar slants were incubated for 10 days.

Gelatin liquefaction was examined in $15 \%$ gelatin in nutrient broth. The cultures were incubated for 18 days at $33^{\circ} \mathrm{C}$ before final reading. Liquefaction of serum was tested for on $83 \%$ bovine serum in nutrient broth, coagulated by exposure to $80^{\circ} \mathrm{C}$ for $2 \mathrm{~h}$. These cultures were incubated for 10 days, and were employed also for detection of pigment production.

Hydrogen sulfide production was studied on Triple Sugar Iron Agar (Difco) and in meat extract peptone agar with $0.1 \%$ lead acetate. The medium for indol production consisted of $2 \%$ Pepton aus Casein (Merck) and $0.2 \% \mathrm{Na}_{2} \mathrm{HPO}_{4}$ in distilled water. The hydrogen sulfide and indol reactions were also performed with $10 \%$ horse serum added to the respective media.

Urease activity was studied according to Blake Christensen (1946), with a very heavy inoculum and daily observations. In parallel another method was used. A heavy suspension of cells was mixed with urea in the following solution: $\mathrm{KH}_{2} \mathrm{PO}_{4}(0.1 \%), \mathrm{K}_{2} \mathrm{HPO}_{4}(0.1 \%)$ and urea $(1 \%)$ in distilled water with phenol red as $\mathrm{pH}$ indicator. The mixture was held at $37^{\circ} \mathrm{C}$ during $24 \mathrm{~h}$. Definite indicator change in 20 min. was recorded as strongly positive, in $4 \mathrm{~h}$ as medium positive, and in $24 \mathrm{~h}$ as weakly positive reaction (Lautrop 1966).

Tests for deamination of phenylalanine and tryptophan were performed according to the impregnated paper strip method of Goldin and Glenn (1962). The impregnation solutions consisted of $0.5 \%$ L-phenylalanine or 1\% L-tryptophan in phosphate buffer, $\mathrm{pH} 7.4$. Readings were made in $1-2 \mathrm{~h}$ at $37^{\circ} \mathrm{C}$ by means of one drop of $8 \%$ aqueous $\mathrm{FeCl}_{3}$.

Antibiotic sensitivity tests were performed in accordance with the method of Ericsson, Hogman and Wickman (1954), further described by Ericsson (1960).

DNA base determinations. Guanine + cytosine $(G+C)$ contents of DNA were determined by Dr. W. Szybalski* with the $\mathrm{CsCl}$ buoyant density method on extracts prepared in the author's laboratory.

* Professor of Oncology, University of Wisconsin. 
Transformation methods. A quantitative procedure with short-term DNA exposure and a more sensitive, but less accurate approach, with continuous DNA exposure, was employed. The principles of mutant selection, transformation techniques, transformant assay and control measures, have been extensively described previously in connection with application of the methods in Moraxella and Neisseria (Bovre $1964 \mathrm{a}, \mathrm{b}, 1965 \mathrm{a}, \mathrm{b}, \mathrm{c}, \mathrm{d}, 1967 \mathrm{a}, \mathrm{b}, \mathrm{c}, \mathrm{d})$. The genetic marker usedwas exclusively one-step mutation to high streptomycin resistance.

\section{Results}

\section{Morphological, cultural and biochemical characteristics}

The microscopic picture most often consisted of small to medium diplococci or short rods occurring singly or in diploforms. Occasionally the dimensions varied vonsiderably in the same preparation. Very thin, and also rather long rods could be seen, as well as curved, uneven, lentiform or lanceolate forms. The microscopic picture of strain $752 / 52$ has been given previously (B 6 vre 1964b). However, in most strains no pleomorphism was observed. Microphotographs of the strains 2863,5542 and $1078 / 55$ are presented in Figures 1,2 and 3 . Small capsules were observed in the only strongly mucoid strain (9413). Motility was not observed. The strains were all Gram-negative, but resistance to decolorization during Gram-staining was often observed. Generally, the microscopic appearance was identical at the two incubation temperatures.

The size of single colonies was of the order $0.5-1.0 \mathrm{~mm}$ in diameter. The strains 752/52, 2863, 9413 and A1019 were almost like $\underline{M}$. nonliquefaciens and $\underline{M}$. osloensis in colony size, whereas the 5 other strains grew with pin-point. colonies on blood agar. The colonies were of the low hemisphaerical to low conical type, with a tendency to form an ir regular edge and a raised center with prolonged incubation. They were almost clear to slightly opaque and also in this respect similar to the two former species. However, the strains $752 / 52,2863$ and Al 019 were a little more greyishly opaque. The consistency of colonies was soft, mucoid or friable. Several strains agglutinated spontaneously in physiological saline. A change from mucoid to friable consistency was observed in one of the strains (752/52). On some batches of blood agar there was a group specific greenish discoloration of the medium, but not on other batches, prob- 

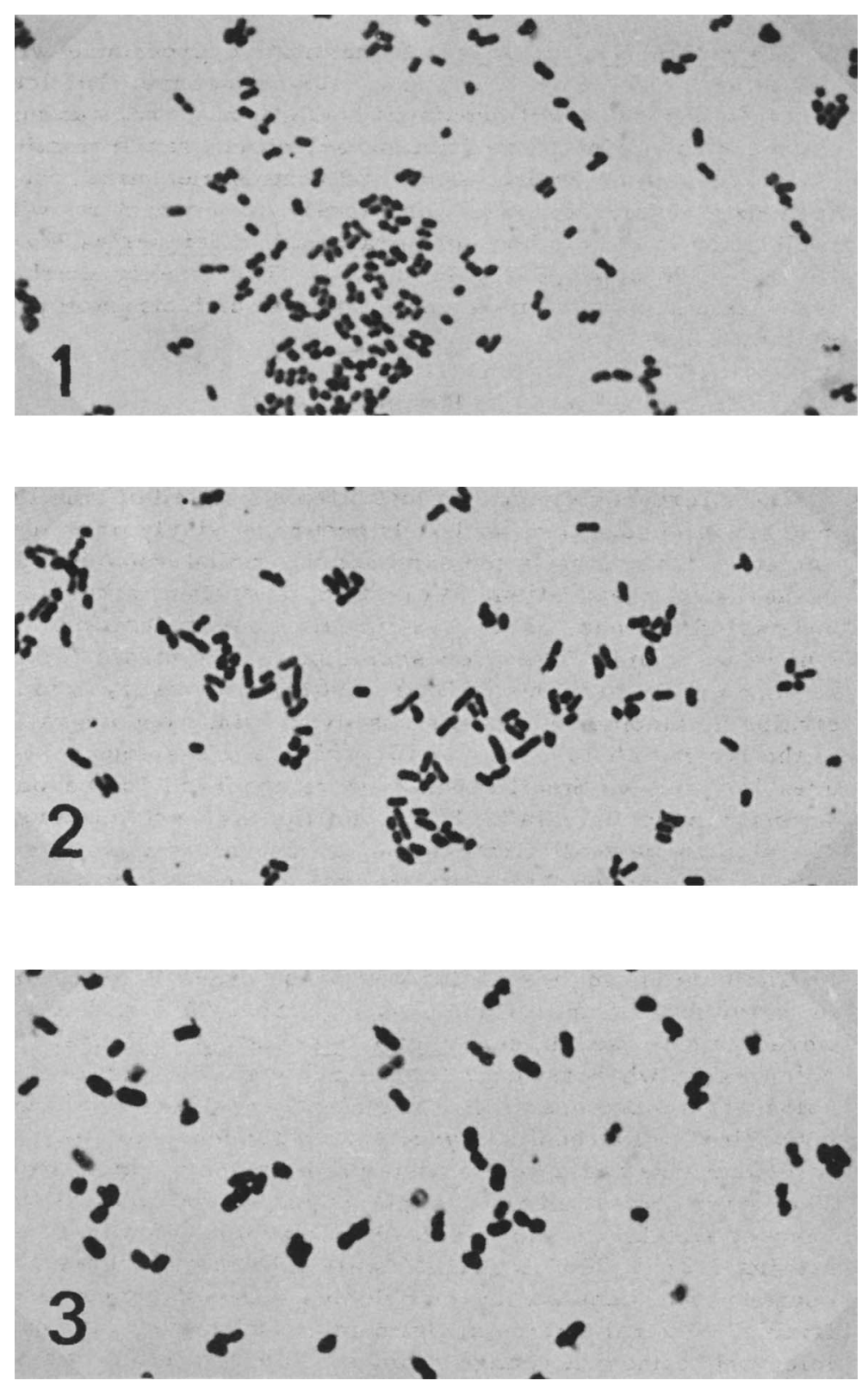

Figure 1. Strain 2863. Figure 2. Strain 5542.

Figure 3. Strain 1078/55. All stained by Gram's method. X 1600 . 
ably depending on $\mathrm{pH}$ differences. There was no beta-haemolysis.

Anaerobic growth was not observed. In stab cultures in semisolid media all strains grew fairly well down to $5 \mathrm{~mm}$ below the surface. Distinct initiation of slight growth occurred aerobically on blood agar at room temperature. Optimal growth appeared at $33^{\circ} \mathrm{C}$ to $37^{\circ} \mathrm{C}$ (in some instances $37^{\circ} \mathrm{C}$ was a slightly superior growth temperature). All strains resisted heating to $53^{\circ} \mathrm{C}$ for $30 \mathrm{~min}$. Two strains $(752 / 52$ and $\mathrm{A} 1019)$ also survived exposure to $57^{\circ} \mathrm{C}$ for 10 min, but the other strains examined were killed by this treatment. All strains survived for at least 40 days on blood agar plates at room temperature.

Catalase activity and a strong oxidase reaction with both reagents were uniform characteristics of the group. No acid production was observed from glucose and maltose. There was no gelatin or serum liquefaction, nor indol production. Growth was poor or absent on unenriched indol and nitrate media. Traces of hydrogen sulfide were produced by some strains in lead acetate media, but not on Triple Sugar Iron Agar. Other results of cultural and biochemical tests are presented in Table 1 . The results of antibiotic sensitivity tests are listed in Table 2.

DNA base composition. The $G+C$ percentage of DNA from the strains $752 / 52$ and 2863 was in both cases 43-43.5, which is similar to that of $\underline{M}$. osloensis, but bigher than that of M. nonliquefaciens.

Transformation. In Table 3 are presented results of quantitative transformation, where the activities of $\underline{M}$. phenylpyrouvica donors on $M$. nonliquefaciens and $M$. osloensis recipients have been compared with intrastrain transformation of the recipients in parallel. The ratios of inter-to intrastrain $t$ ransformation of $M$. nonliquefaciens are below $1.4 \times 10^{-5}$, and with $\underline{M}$. osloensis recipient below $8.3 \times 10^{-6}$. Simultaneously performed experiments with continuous exposure of $\underline{M}$. nonliquefaciens to the $\underline{M}$. phenylpyrouvica DNAs were also negative (not tabulated). This latter finding indicates that the ratio of inter- to intrastrain transformation between $\underline{M}$. nonliquefaciens and $\underline{M}$. phenylpyrouvica are actually of the order $10^{-6}$ or lower (see Bovre 1967d).

M. osloensis, Neisseria catarrhalis and $N$. ovis were exposed continuously to DNAs of $\underline{M}$. phenylpyrouvica. For comparative purposes donors of known low compatibilities with the respective recipients were included in parallel (see Bovre 1967a). The results are presented in Table 4 . Some 
350 SYSTEMATIC BACTERIOLOGY

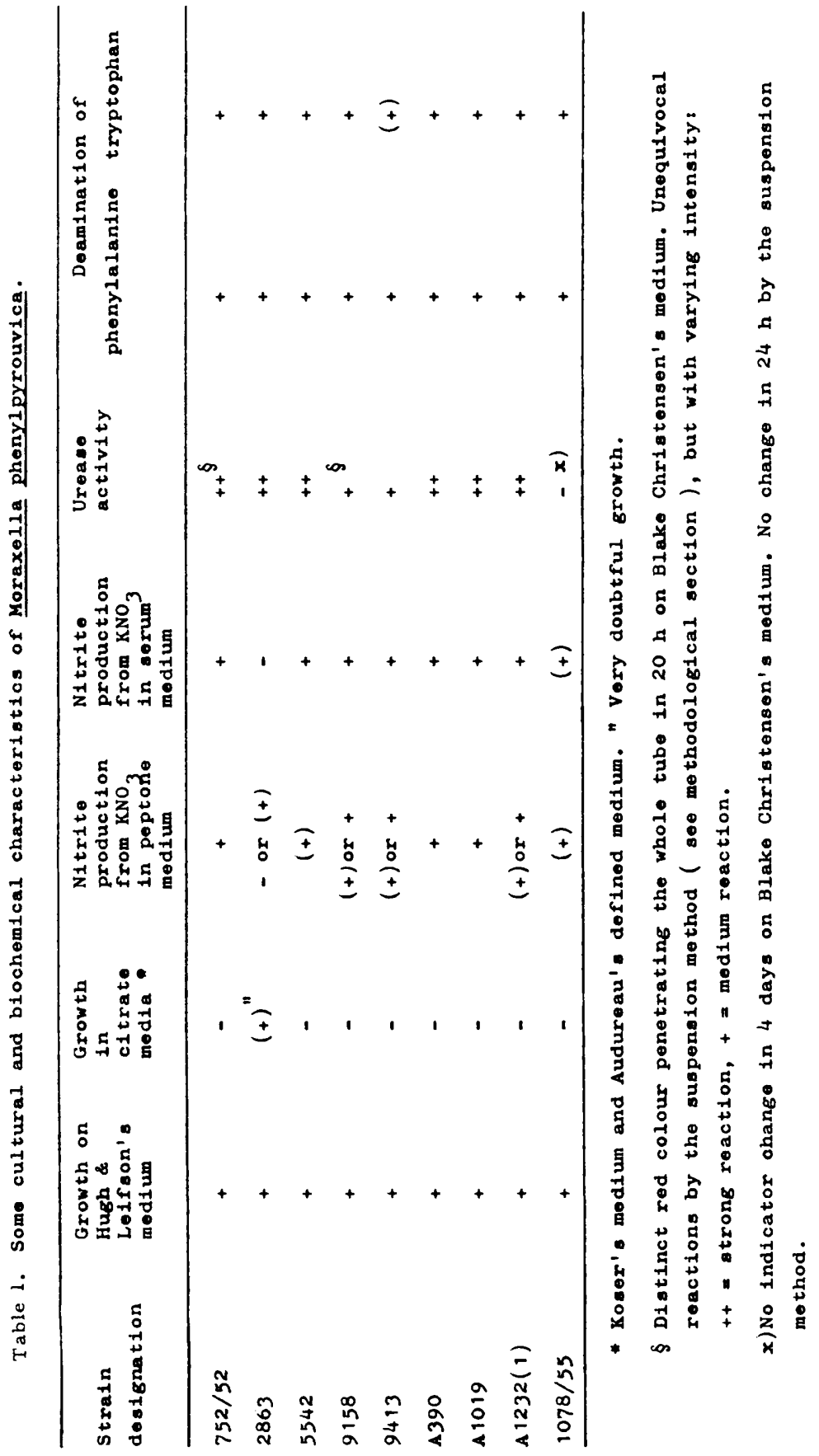


Table 2. Sensitivity to antibiotics of the nine strains of Moraxella phenylpurouvica.

\begin{tabular}{llc}
\hline Antibiotic & $\begin{array}{l}\text { Range of } \\
\text { inhibition } \\
\text { zones in mm } \\
\text { diameter }\end{array}$ & $\begin{array}{l}\text { Approximate range } \\
\text { of minimum inhibitory } \\
\text { concentrations } \\
\text { (m. i.c.) }\end{array}$ \\
\hline $\begin{array}{l}\text { Penicillin } \\
\text { Streptomycin }\end{array}$ & $19-43$ & $0.04-<0.005$ \\
Chloramphenicol & $30-35$ & $5-0.2$ \\
Oxytetracycline & $28-33$ & $0.5-0.2$ \\
Erythromycin & $22-28$ & $0.2-0.03$ \\
\hline
\end{tabular}

* Method of Ericsson, Hogman and Wickman (1954). M. i. c. values calculated from zone diameters by means of regression equations for each antibiotic (Ericsson 1960). M. i.c. given as I. U. $/ \mathrm{ml}$ for penicillin, as $\mu \mathrm{g} / \mathrm{ml}$ for the other antbiotics. 


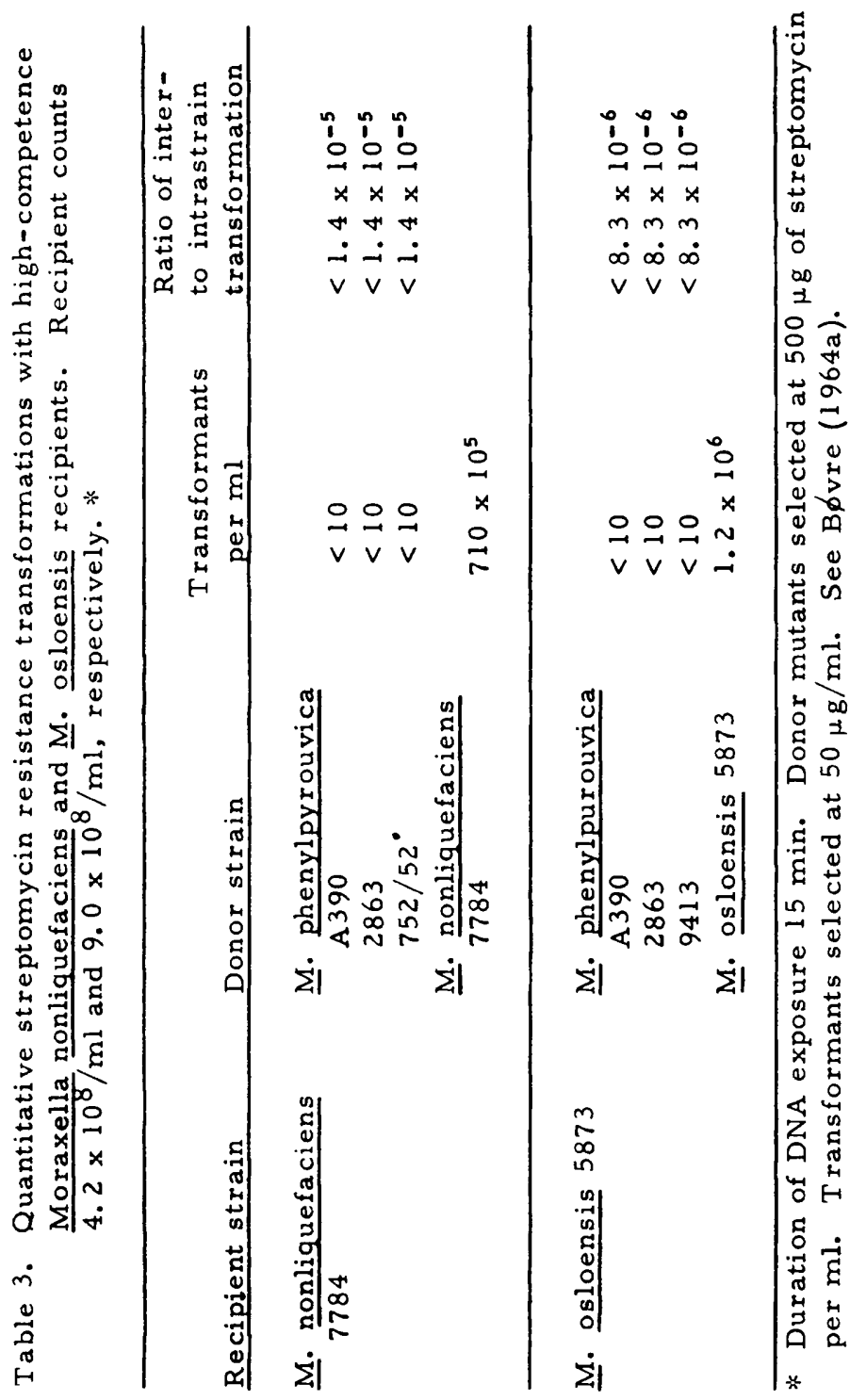




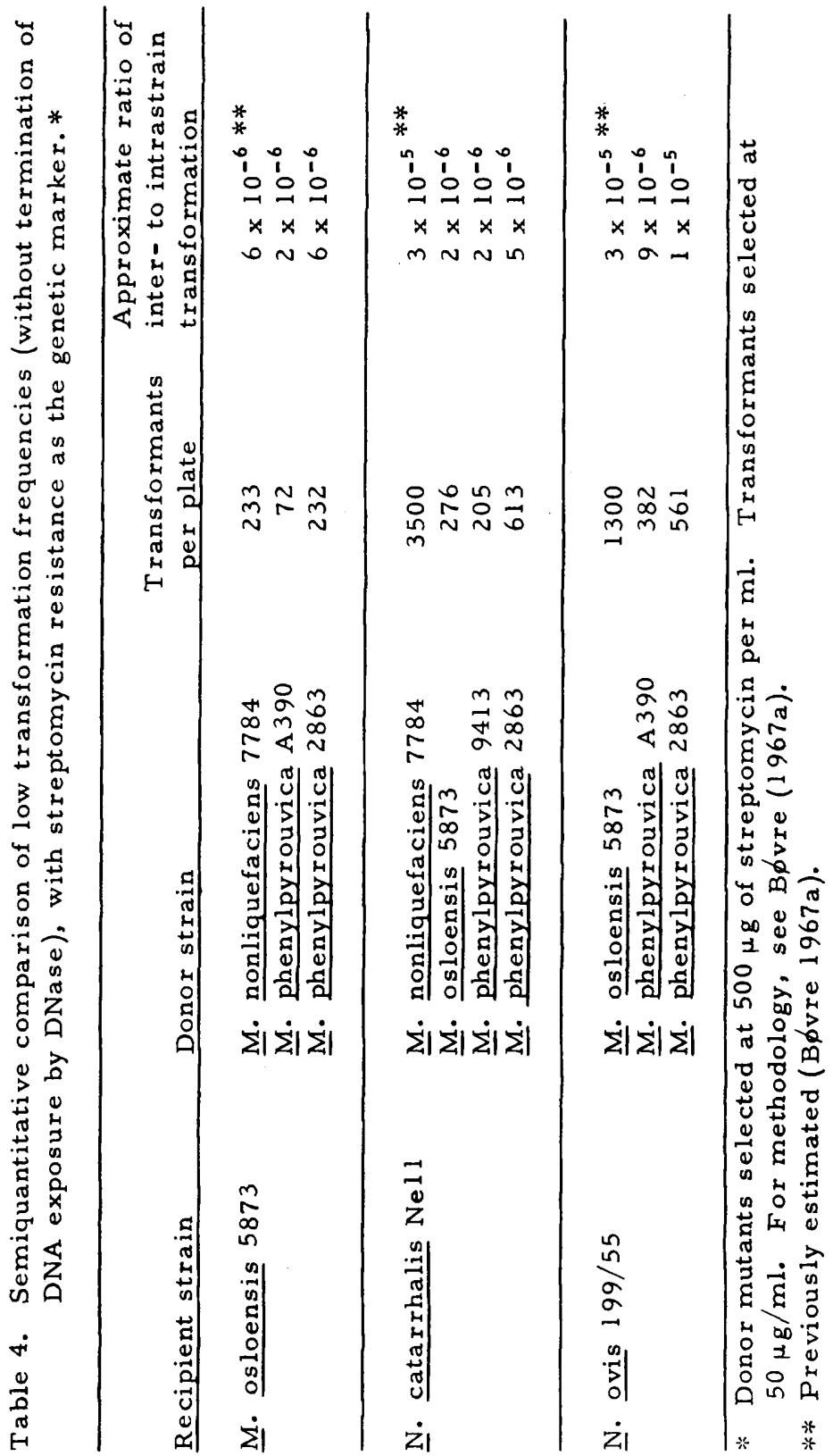


very slight compatibilities are observed, which may be expressed by ratios of inter- to intrastrain transformation ranging from $2 \times 10^{-6}$ to $1 \times 10^{-5}$ between $\underline{M}$. phenylpyrouvica and the former recipients.

None of the $\underline{M}$. phenylpyrouvica strains were transformable under the conditions of the procedure. With strain $1078 / 55$ numerous attempts at isolation of streptomycin resistant mutants failed, so that this strain could be used neithe $r$ as recipient nor as donor in transformation.

The strain $752 / 52$ has previously been employed as donor in transformation with $\underline{M}$. nonliquefaciens, $\underline{M}$. osloensis, $\underline{M}$. bovis and serum-liquefying, nonhaemolytic moraxellae (Bфvre 1964b, 1965a,c). These studies revealed no compatibilities.

Description of Moraxella phenylpyrouvica

Micromorphology: Short rods, most often occurring as diplobacilli of slightly smaller dimensions than $\underline{M}$. nonliquefaciens. Often somewhat irregular in thickness and shape of individual cells. Gram-negative, with some tendency to resist decolorization. Nonmotile, no endospores. May be encapsulated.

Colonies: On blood agar of pin-point size to $1 \mathrm{~mm}$ in diameter in $20 \mathrm{~h}$, thus being smaller than those of $\underline{M}$. nonliquefaciens. Low convex, with a tendency to form an irregular edge with a raised center on prolonged incubation. Slightly opaque or almost clear. No pigment. Soft, mucoid of friable consistency. Nohaemolysis, but sometimes greenish discoloration of blood agar.

Relation to oxygen: Strict ae robe.

Temperature: Slight growth at room temperature, optimal growth at c. $33^{\circ} \mathrm{C}$ to $37^{\circ} \mathrm{C}$. Less sensitive to heat than M. nonliquefaciens, regularly resisting exposure to $53^{\circ} \mathrm{C}$ for $30 \mathrm{~min}$. and being killed by exposure to $57^{\circ} \mathrm{C}$ for $20 \mathrm{~min}$.

Growth requirements: Poor growth in fluid peptone media without aeration, but grows well on the surface of Hugh and Leifson's medium. Usually no growth in Koser's citrate and in Audureau's defined medium.

Longevity: Remains alive on blood agar at room temperature for at least 40 days.

Biochemical reactions: Catalase reaction positive. Oxidase reaction positive with dimethyl- and tetramethyl-pphenylenediamine. Nitrates usually reduced to nitrites, with occasional exceptions and some weak reactions. No acid 
from carbohydrates (glucose and maltose). Gelatin and serum not liquefied. No indol and usually no hydrogen sulfide production. Rapid splitting of urea and easily detectable deamination of phenylalanine and tryptophan.

Antibiotic sensitivity: High to moderate sensitivity to penicillin, streptomycin, chloramphenicol, oxytetracycline and e rythromycin.

Habitat: Uncertain. Strains have been isolated from genitourinary tract, blood, cerebrospinal fluid and pus of various lesions.

Pathogenicity: Unknown.

DNA base composition: Percentage of guanine + cytosine of the order 43-43.5 (CsCl buoyant density method).

Genetic compatibilities: Transformable strains not observed. Very slight compatibility in streptomycin resistance transformation with recipients of $\underline{M}$. osloensis (highest ratio of inter- to intrastrain transformation approximately $\left.6 \times 10^{-6}\right), \underline{N}$. catarrhalis (highest ratio $5 \times 10^{-6}$ ) and $N$. ovis (highest ratio $\left.1 \times 10^{-5}\right)$. No compatibility with $\mathrm{M}$. nonliquefaciens observed (ratios most probably below 10-6).

\section{Discussion}

Except for the description of strain 752/52 (Bळvre 1964b) consistently urease positive moraxellae have not previously been reported in the literature. The same holds for oxidative deamination of phenylalanine and tryptophan, which seems almost specific for this species as far as oxidase positive organisms are concerned. This statement is based on a large series of unpublished observations on a variety of such organisms in this laboratory.

However, as already mentioned, we found that the only existing strain of Moraxella polymorpha described by Flamm also deaminated these amino acids. This strain behaved as our other strains morphologically, culturally and biochemically, except that it failed to split urea. It was also interesting that this strain now completely lacks the polymorphism which characterized it, when it was described. This suggests that this strain must be considered to belong to the same species as our other strains. It is true that it differs from the other strains in failing to split urea, but we feel that a difference only in this single character is insufficient to place it in a separate taxon. Experience with Proteus and Providence suggests the possibility that deamination of amino acids may be a more stable biochemical trait than 
urease production. Thus urease negative, but not phenylalanine negative Proteus strains are known, and Providence strains are consistently urease negative. This analogy may not be relevant, but the fact remains that the strain $1078 / 55$ only differs from the other strains in one of the characters studied. The relationship of this strain to the other strains might perhaps be clarified by other genetic means than transformation, e.g. nucleic acid hybridization experiments.

Assuming that the strain 1078/55 does belong to the same species, the obvious conclusion would be to use the name Moraxella polymorpha on this species. We feel, however, that the use of this name would be bound to cause considerable confusion, and that it is probable that the epithet polymorpha is illegitimate in this combination.

De Bord $(1939,1942)$ gave the name Mima polymorpha to a group of organisms showing morphological similarity to Neisseria gonorrhoeae. It seems very probable that the oxidase positive variety of this species, $\underline{M}$. polymorpha var. oxidans, may actually have been a Moraxella, but since no cultures of this species have been maintained, and since De Bord did not examine the characters now available to distinguish between the various Moraxella species, it is quite impossible to find out just what organism De Bord worked with. It may have been one of the species of Moraxella known today, or it may have been one of the so far unidentified oxidase positive organisms which are known to exist. Therefore the variety oxidans may have been the same or a different Moraxella species than $\underline{M}$. polymorpha. De Bord's description of the growth characteristics of his organisms suggests that it was a different species ("growth on plain agar is abundant, white, glistening, smooth, viscid, ..."). If, as seems probable, Mima polymorpha var. oxidans was another Moraxella species, than $\underline{M}$. polymorpha, the latter epithet is illegitimate as a later homonym according to rule $24 \mathrm{~d}$ of the International Code of Nomenclature of Bacteria (1966).

Henriksen (1963) has previously suggested that the epithet polymorpha in the combination Mima polymorpha be rejected, by the conservation of the epithet lwoffi, and has requested an Opinion from the Judicial Commission on this point. If this suggestion is approved, the epithet of Mima polymorpha becomes illegitimate. But according to the same rule, this would not improve the standing in nomenclature of the epithet polymorpha in Moraxella polymorpha: "Even if the earlie $r$ homonym is illegitimate, or is generally treated 
as a synonym on taxonomic grounds, the later homonym must be rejected." We conclude that the epithet polymorpha in the combination Moraxella polymorpha appears to be illegitimate.

Before we were aware of the fact that Flamm's Moraxella polymorpha belonged to the same species as our strains, we had the intention of naming the species Moraxella phenylpyrouvica. We feel that this is a suitable name, since deamination of phenylalanine appears to be a very rare character, and we propose that this name be adopted.

We feel that this is a matter that should be referred to the Judicial Commission, and we therefore request Opinions on the following two questions:

1. Should the name Moraxella polymorpha be placed on the list of nomina rejicienda according to Principle $1(2)$ and Rule $24 \mathrm{~d}$ of the International Code of Nomenclature of Bacteria?

2. Should the name Moraxella phenylpyrouvica be conserved against Moraxella polymorpha?

The strain $1078 / 55$ was the first strain to be described, and it would have been the natural choice of a type strain. However, the fact that it differs from the other strains in failing to split urea raises some doubt as to the relationship of this strain to the others, and we therefore feel that it would be safer to select an entirely typical strain as a neotype strain. We propose that the strain 2863 be designated as the neotype strain of Moraxella phenylpyrouvica. This strain has been thoroughly examined and is a strong urease producer. It is being deposited in the National Collection of Type Cultures and in the American Type Culture Collection. (As we go to press we learn that this neotype strain has been assigned the ATCC accession number 23333, and also NCTC number 10526.) 


\section{References}

Audureau, A. 1940. Etude du genre Moraxella. Annales de l'Inst. Pasteur 64:126-166.

Blake Christensen, W. 1946. Urea decomposition as a means of differentiating Proteus and paracolon cultures from each other and from Salmonella and Shigella types. J. Bacteriol. 52:461-466.

B $6 v$ re, K. 1964a. Studies on transformation in Moraxella and organisms assumed to be related to Moraxella. 1 . A method for quantitative transformation in Moraxella and Neisseria, with streptomycin resistance as the genetic marker. Acta Path. et Microbiol. Scand. 61: 457-473.

- 1964b. Studies on transformation in Moraxella and organisms assumed to be related to Moraxella. 2. Quantitative transformation reactions between Moraxella nonliguefaciens strains, with streptomycin resistance marked DNA. Acta Path. et Microbiol. Scand. 62:239248.

- 1965a. Studies on transformation in Moraxella and organisms assumed to be related to Moraxella. 3. Quantitative streptomycin resistance transformation between Moraxella bovis and Moraxella nonliquefaciens strains. Acta Path. et Microbiol. Scand. 63:42-50.

- 1965b. Studies on transformation in Moraxella and organisms assumed to be related to Moraxella. 4. Streptomycin resistance transformation between asaccharolytic Neisseria strains. Acta Path. et Microbiol. Scand. 64:229-242.

- 1965c. Studies on transformation in Moraxella and organisms assumed to be related to Moraxella. 5. Streptomycin resistance transformation between serum-liquefying, nonhaemolytic moraxellae, Moraxella bovis and Moraxella nonliquefaciens. Acta Path. et Microbiol. Scand. $65: 435-449$.

- 1965d. Studies on transformation in Moraxella and organisms assumed to be related to Moraxella. 6. A distinct group of Moraxella nonliguefaciens-like organisms (the "19116/51" group). Acta Path. et Microbiol. Scand. 65: $641-652$. 
- 1967a. Studies on transformation in Moraxella and organisms assumed to be related to Moraxella. 7. Affinities between oxidase positive rods and neisseriae, as compared with group interactions on both sides. Acta Path. et Microbiol. Scand. 69:92-108.

- 1967b. Studies on transformation in Moraxella and organisms assumed to be related to Moraxella. 8. The relative position of some oxidase negative, immotile diplobacilli (Achromobacter) in the transformation system. Acta Path. et Microbiol. Scand. 69:109-122.

- 1967c. Transformation and DNA base composition in taxonomy, with special reference to recent studies in Moraxella and Nei sseria. Acta Path. et Microbiol. Scand. 69:123-144.

- 1967d. Moraxella and Neisseria. Transformation, DNA analysis and taxonomy. Universitetsforlaget, Oslo (Thesis, $30 \mathrm{pp}$. + the 9 above-mentioned articles). and S. D. Henriksen. 1967a. A new Moraxella species, Moraxella osloensis, and a revised description of Moraxella nonliquefaciens. Internatl. J. Syst. Bacteriol. 17:127-135. and - 1967b. Recognition of three new bacterial groups, considered as species of Moraxella. XV Scandinavian Congress for Pathology and Microbiology, Copenhagen, 1967. Acta Path. et Microbiol. Scand. Suppl. 187:11-22.

De Bord, G. G. 1939. Organisms invalidating the diagnosis of gonorrhea by the smear method. J. Bacteriol. 38: 119-120.

- 1942. Descriptions of Mimeae trib. nov. with three genera and three species and two new species of Neisseria from conjunctivitis and vaginitis. Iowa State Coll. J. Sci. $16: 471-480$.

Ericsson, H. 1960. Rational use of antibiotics in hospitals. Studies on laboratory methods and discussion of the biological basis for their clinical application. Scandinav. Jour. Clin. Lab. Invest. 12:(Suppl. 50).

, C. Hфgman and K. Wickman. 1954. A paper disk method for determination of bacterial sensitivity to chemotherapeutic and antibiotic agents. Scandinav. Jour. Clin. Lab. Invest. 6:(Suppl. 11).

Flamm, H. 1957. Eine weitere neue Species des Genus Moraxella M. polymorpha sp. n. Zentr. Bakt., I Abt., Orig. $168: 261-267$. 
Goldin, M. and A. Glenn. 1962. A simple phenylalanine strip method for identification of Proteus strains. J. Bacteriol. 84:870-871.

Henriksen, S. D. 1963. Mimeae. The standing in nomenclature of the names of this tribus and of its genera and species. Internatl. J. Syst. Bacteriol. 13:51-57.

Hugh, R. and E. Leifson. 1953. The taxonomic significance of fermentative versus oxidative metabolism of carbohydrates by various Gram negative bacteria. J. Bacteriol. 66:24-26.

King, E. O. 1965. Personal communication.

Koser, S. A. 1924. Correlation of citrate utilization by members of the colon-aerogenes group with other differential characteristics and with habitat. J. Bacteriol. 9:59-77.

Lautrop, H. 1966. Personal communication. 